\title{
Emergency Coordination Decision-Makers Evaluation and Selection Based on Multi-Attribute Group Decision Model
}

\author{
Haixia Wang1, Lin Wang², Yunxian Hou' ${ }^{1}$ \\ ${ }^{1}$ College of Economics and Management, China Agriculture University, Beijing, China \\ ${ }^{2}$ School of Management, Henan University of Technology, Zhengzhou, China \\ Email:whx7903@126.com
}

How to cite this paper: Wang, H.X., Wang, L. and Hou, Y.X. (2017) Emergency Coordination Decision-Makers Evaluation and Selection Based on Multi-Attribute Group Decision Model. Journal of Service Science and Management, 10, 43-53.

https://doi.org/10.4236/jssm.2017.101004

Received: February 10, 2017

Accepted: February 21, 2017

Published: February 24, 2017

Copyright $\odot 2017$ by authors and Scientific Research Publishing Inc. This work is licensed under the Creative Commons Attribution International License (CC BY 4.0).

http://creativecommons.org/licenses/by/4.0/

\begin{abstract}
The sudden disasters often cause serious consequences; the research on emergency decision becomes a focus, and emergency collaborative decision-making is becoming a hot spot. Sudden disasters emergency behavior usually involves many departments, so it is necessary to evaluate and select the cooperative decision-makers in the process of collaborative decision-making, the appropriate cooperative decision-makers play an important role in the emergency rescue operation. Based on this, we analyze emergency collaborative decision-making subject influence factors under the sudden disaster, and design the index system for the Evaluation and Selection of emergency collaborative decision-makers, and solve the evaluation model by the method of multi-attribute group decision-making.
\end{abstract}

\section{Keywords}

Emergency Decision, Collaborative Decision, Decision-Makers, Multi-Attribute Group Decision Model

\section{Introduction}

Since the 21st century, the global human continuously suffered the invasion of earthquakes, floods, landslides, frozen, tsunamis and other natural disasters and all kinds of malignant disease and other kinds of public emergency, which pose a serious threat to people's lives and property security. For example, in 2003 the SARS epidemic swept the country, the end of 2004 in the Indian Ocean earthquake and tsunami, in August 2005 the United States in the south of the "Katrina" hurricane, early 2008 occurred in southern China's snowstorms and 2008 Sanlu milk powder incident and May 12 occurred in Wenchuan, Sichuan Prov- 
ince, China's 8.0 magnitude earthquake. In 2009, the global spread of influenza A H1N1 influenza. 7.3 strong earthquake in Haiti. The 7.1 earthquake in Yushu, Qinghai and the large debris flow in Zhouqu, Gansu in 2010 as well as the 2011 motor vehicle crash in Wenzhou, "3.11" Richter 9.0 earthquake in Japan, and the resulting nuclear leakage events, etc. These massive sudden public emergencies to the affected areas of economy, people's lives and property caused heavy losses.

Emergencies occur frequently makes the emergency management become a focus of global attention, how to make the most efficient emergency decisionmaking has been a common topic that countries around the world face. Emergency decision-making is a multi-decision-making decision-making body involved in the decision-making behavior, decision-making with a consistent decision objective, each decision-making fully share information in decision, fully understand the emergency situation and restriction conditions, so as to make effective decisions, to win more multilateral decision-making satisfactory results. Can be seen from this, emergency decision reflects the cooperative way of decision, but compared with the general meaning of coordinated decision, more emphasis on time and resource constraints of punitive, the need to further improve the existing collaborative decision-making theory, in order to better guide the decision-making activities of emergency situation.

At present, foreign countries have a wide range of research subjects for decision-making, involving many areas. Some from the method point of view of the decision-makers to study, and some studies focus on the impact of decisionmakers of the frame effects, as well as from the perspective of the complexity of decision-making groups to study, and on the aspects of the decision-making body weight were studied. In terms of method, Elfithri R., Mokhtar M. B., by means of the characteristics of the Malay archipelago Langat basin, from the perspective of coordinated decision, studied the cross-regional integrated water resources management, points out that the integrated water resources management of coordinated decision participants including government agencies, nongovernmental organizations, private structure, publics, universities, society, water resource users and other stakeholders, based on cooperation, communication, share information, exchange information, work together, widely participate in collaborative decision-making, such as the analysis of the key elements to achieve fast and efficient and reasonable comprehensive water resources [1]. Bernier J. used the Bayesian method to research the decision-making behavior in the hydrological risk decision and policy makers [2]. Manassero G. in order to solve the equipment selection in the uncertainty of decision-making process involved in the decision-making problem, using the analytic hierarchy process to the decision-making management [3]. In addition, in terms of the complexity of the decision-making plan selection, F. Herrera, put forward that in the process of group decision choice, mainly reflected in three aspects: decision-making group preference statement and exchange group massing and scheme selection preferences.

At present, our country in the field of emergency decision-making is mainly 
research the specific accident emergency coordination, focus on the research the coordination mechanism of emergency decision system, emergency department linkage mechanism and the study of emergency resource conflict coordination. Huang Dian-jian, Li Chuan-gui studied the major accident emergency coordination mechanism, city major accident emergency coordination model is established [4]. Tan Xiao-qun, Chen Guo-hua studied the mechanism of emergency coordination to cross-regional, and from the organization, laws, regulations, cross-regional emergency culture, resources and technical support five aspects discusses the realization ways of cross-regional emergency coordination mechanism, the effect of emergency response [5]. Kang Kai, Chen Tao, Yuan Hongyong proposed the concept of multilateral collaborative decision-making of emergency decision-making, studied the emergency resources cooperative decisionmaking and group decision-making of emergency rescue of coordinated decision in the process of emergency plan optimization, and various emergency collaborative decision-making is defined as the sudden incident, in the time urgent circumstances, collect information processing, and emergency decision making problems with clear objective, negotiation and formulate alternatives set, to seek the best collaborative scheduling scheme, organize implementation and constantly track inspection, timely and correct the mistakes in the decision making process, until the problem solve a dynamic decision process [6]. Chen Xing, Wang Yong, Wu Ling-yun combined with dynamic department coordination and decision-making, define the synergy matrix, coordination coefficient and so on some new concepts about emergency coordinated decision, and build the multi-stage multi-objective multi-sectoral collaborative decision-making model in emergency [7]. Du Lei for multiple cooperating organization in the process of emergency disposal problems, the use of multiple cooperating Agent and Petri net model to define the problem, research the basic structure of Petri net model within the Agent and using the model of collaborative interaction relation adjustment Agent more work together [8]. Liu Yi, Zhou Qi, et al. by adopting the method of Multi-Agent in the snow disaster in 2008 typical multi-sectoral collaborative modeling and analysis together, the weak strong synergy and synergy of three different coordination mechanism for emergency response to effect [9]. Liu Hong-qin, Sha Yong-zhong, Liu Qiang (2011) further analyzes the public emergency coordination mechanism, combining with the earthquake cases, life cycle from public crisis types, emergency disposal and emergency management organization structure three sides, this paper expounds the emergency disposal of coordination mechanism in the process of the formation of the way [10].

Through literature both at home and abroad study found that, domestic and overseas for emergency management, especially major workplace accident emergency auxiliary support system, emergency resource scheduling, the crowd evacuation problems made a lot of practice and theory research, the focused in other emergency management research. Although academia and government management in emergency management has been a lot of research and practical op- 
eration experience, some still not solve the fundamental problem, the efficiency of emergency management is not on the actual public emergency is able to fully embody. As in the emergency management decisions subject selection, participate in power is mainly limited to government departments and the affected unit of emergency power, to use and guidance is of rich resources and power in society to participate in the emergency management research institute, see few; In terms of the rescue efficiency of emergency management, how to improve the rescue efficiency of emergency management, the coordination of emergency resources scheduling, strengthen the order rescue process, to coordinate the rescue participate in the collective action of main body, improve the ability to participate in the joint collaboration between organizations or individuals, as well as the analysis of emergency situations emergency group negotiation process and scheme of quantitative or qualitative research also need to be further in-depth study.

Therefore, this article will research on the evaluation and selection of emergency coordination decision-makers. We first analyzes the factors affecting the decision-making body of emergency coordination, establish the evaluation index system, and then design the multiple attribute group decision making method for solving emergency collaborative decision-making selection model.

\section{Model Formulation}

\subsection{Problem Description}

Emergency coordinated decision suggests that in emergencies, there is always spontaneous decision-making aid consciousness, at the same time, more or less with other decision-making subject connection and the formation of a coordinated emergency practice. At the beginning of the emergency happened, the correlation of various decision-making subject is very small, and the whole rescue practice can present a state of disorder. But as the core of decision-making to step in and rescue practice achieved fully mobilized, the correlation of various decision-making body is enhanced, and the independence of the various decision-making body in subdued. When the whole rescue practice in a fully active, each decision-making relating to become dominant, emergency disaster loss no longer increases, constantly improve the emergency rescue efficiency, to enhance collaborative between decision-making. Therefore, in the process of the collaborative continuously strengthen, needs to participate in the decision-making of the decision-making evaluation and selection, in order to realize the overall sequential collaborative.

\subsection{Emergency Collaborative Decision-Making Influence Factors Analysis}

\subsubsection{Decision-Making Capacity}

Emergency decision-making mainly in the level of management decision-making, both the strategic decision-making and operational decision-making part of the characteristics of the face are mostly unstructured issues. Emergency deci- 
sion-making capacity of the core components of the core of four, respectively, for the strategic sense of the capacity to judge and control, as well as operational significance of the action and organizational capacity.

1) Accurate judgment capacity based on comprehensive quality of decisionmaking subject

This judgment not only required in the process of decision-making can be rational, objective and unbiased attitude direct judgment, but also requires the decision-making subject can carry on the risk assessment to the complicated situation, make complex judgment based on limited information. No matter in which part of emergency response work, decision-making subject needs to be based on the limited information, first of all to event situation and development trend of overall comprehensive judgment. Specific indicators include the amount of information, the time of judgment, accuracy, etc.

2) The specific content of the decision-making quickly put into action the ability to act

Good action capacity firstly includes a based on the response will determine the accurate judgment of the ideas into a feasible solution, and quickly implement and promote the process. Different decision makers on the basis of similar isolation thinking of hazard specific measures taken by the often are quite different. The specific indicators including: the time of reaction, the time of action, the effect of action.

3) The organizational capacity of effectively mobilize all aspects of social forces to participate to response

The organizational capacity is mainly embodied can make full use of a particular time and space under the condition of limited resources in the decisionmaking process, and emergency decision making includes effective scheduling of all resources and power. Specific indicators include task assignment, persuasion guidance, and social participation.

4) For their psychological and rhythm of action until the whole situation of the control capacity

Control is mainly to supervise, comparing and correcting work process. Decision-making subject is facing the more urgent and complicated things, once won't be able to keep a clear mind and their own psychological and action has strong rhythm control, also won't be able to achieve the ultimate control over the whole situation, thus the whole emergency response work might walk into trouble or directly result in failure. The decision makers control of the rhythm of the specific actions require both on the basis of subjective judgment and objective events at the same time also need to deal with the working conditions and requirements as the guidance. Specific indicators include self-control, rhythm control and state control.

\subsubsection{Participate Capacity}

Participate capacity is mainly affected by the decision-making environment, resource input, degree of recognition of decision-making program, cooperative 
decision-making stability.

1) The decision environment factors, mainly including the ecological environment, natural environment, cultural environment factors, and legal policy factors, such as the strength of decision rules in the process of supervision, decision-making environment on the influence of the decision-making behavior, etc.

2) Resource input, including can be used for emergency decision-making and rescue funds resources, facilities, information platform, etc.

3) The degree of recognition of the decision-making program, said the decision ability of recognition and enforcement.

4) The cooperative decision-making stability, refers to a collaborative decision-making between the coordinated decision will cause a huge wave.

\subsubsection{Synergy Capacity}

The decision-making of the collaborative relationship between collaborative relationships not only include the decision-making, but also includes the decision-making with a series of coordination of relationship between the decision-making, these relations belong to indirect collaborative relationship. Affect the ability of the collaborative key attributes and indicators including decision information transparency, decision subject substitution, process synergy, the degree of mutual support among subjects.

1) Decision-making information transparency is used to represent the decision-making information sharing between the level and quality.

2) The decision-making subject alternative when in collaborative decisionmaking, don't have to back the desired synergy of decision-making, the need to replace by other decision-making ability, so as to ensure a smooth process of coordinated decision.

3) Collaborative process, collaborative decision-making process of interaction and integration, said the decision-making process in the degree of tacit cooperation between the subjects.

4) The degree of mutual support among subjects, the decision-making, the association rules between interaction and mutual influence relationship among decision-making subjects.

\subsection{Emergency Decision-Making Evaluation Index System to Build Together}

Through the above-mentioned emergency collaborative decision-making influence factors analysis, sorting can draw emergency collaborative decision-making subject evaluation indicator system, which is shown in Table 1, at the same time also reflects the influence of emergency coordinated decision attribute characteristics of subject selection, provide framework for emergency collaborative decision-making subject evaluation and selection.

\section{Method}

In establishing the evaluation indicator system of emergency management 
Table 1. Emergency collaborative decision subject evaluation indicator system.

\begin{tabular}{|c|c|c|}
\hline First level indicators & Second level indicators & Third level indicators \\
\hline \multirow{12}{*}{ Decision-making capacity } & & Amount of information \\
\hline & Judge capacity & The time of judgement \\
\hline & & Accuracy \\
\hline & & The time of reaction \\
\hline & Action capacity & The time of action \\
\hline & & The effect of action \\
\hline & & Task assignment \\
\hline & Organizational capacity & Persuasion guidance \\
\hline & & Social participation \\
\hline & & Self-control \\
\hline & Control capacity & Rhythm control \\
\hline & & State control \\
\hline \multirow{6}{*}{ Participate capacity } & $\begin{array}{l}\text { Decision-making } \\
\text { environment }\end{array}$ & $\begin{array}{l}\text { The supervision intensity of } \\
\text { regulations in decision } \\
\text { The influence of decision-making } \\
\text { environment on decision-making }\end{array}$ \\
\hline & & Capital investment \\
\hline & Resource input & Facilities and equipment \\
\hline & & Information platform \\
\hline & $\begin{array}{l}\text { Degree of recognition of } \\
\text { decision-making program }\end{array}$ & \\
\hline & $\begin{array}{c}\text { Cooperative } \\
\text { decision-making stability }\end{array}$ & \\
\hline \multirow{4}{*}{ Synergy capacity } & $\begin{array}{l}\text { Decision information } \\
\text { transparency }\end{array}$ & \\
\hline & Decision subject substitution & \\
\hline & Process synergy & \\
\hline & $\begin{array}{l}\text { The degree of mutual support } \\
\text { among subjects }\end{array}$ & \\
\hline
\end{tabular}

coordination of decision-making subject, can more effectively to the decisionmaking subject evaluation and choice. Process is as follows: first of all, the emergency committee established evaluation team, each member hereby respectively to multiple emergency rescue in the subject of the various indicators to evaluate attributes; Then, gather each member of each participation subject of each attribute value, it is concluded that the emergency committee for each participation subject comprehensive evaluation; Finally, according to each participation subject of the evaluation results to choose according to certain requirements.

Due to participate in the subject of the property is not easy to accurately 
quantify, appropriate uses ordinal number method, namely the emergency committee members first according to the attributes of each sort to choose subject, to gather various properties of the subject of the sorting result, and then according to the weight of each attribute the ranking, the general subject according to the situation to make decisions subject selection.

So, can adopt the following multiple attribute group decision making model:

Set up emergency committee evaluation team has $L$ members, to evaluate the $M$ optional subject, evaluation criteria (attributes) has $N$, the weight of each attribute is $\omega_{n}$, meet the $\sum_{n=1}^{N} \omega_{n}=1$, in which it is $\omega_{n}>0(n=1,2, \cdots, N)$.

Set used by each member of the evaluation criteria, the same power of each committee member of the same, they have the same importance to the evaluation of each subject. The decision-making subject evaluation and selection process is as follows:

Step 1: get the $l$ member of the evaluation of each attribute optional subject sort matrix $A^{l}=\left[a_{m n}^{l}\right]_{M \times N}$

$$
A^{l}=\left[\begin{array}{cccc}
a_{11}^{l} & a_{12}^{l} & \cdots & a_{1 n}^{l} \\
a_{21}^{l} & a_{22}^{l} & \cdots & a_{2 n}^{l} \\
\cdots & \cdots & & \cdots \\
a_{m 1}^{l} & a_{m 2}^{l} & \cdots & a_{m n}^{l}
\end{array}\right], l=1,2, \cdots, L
$$

Among them, $a_{m n}^{l}\left(a_{m n}^{l} \in\{1,2, \cdots, M\}\right)$ said the $l(l=1,2, \cdots, L)$ member according to the $n(n=1,2, \cdots, N)$ attribute to evaluate all optional subject after, The $m(m=1,2, \cdots, M)$ alternative ranking position. Sort the smaller $a_{m n}^{l}$, that is, the more, said the property, the optimal.

Step 2: it is concluded that evaluation group according to the $n$ attribute to all optional subject evaluation matrix after sorting $B^{n}=\left[a_{m n}^{l}\right]_{M \times L}$.

$$
B^{n}=\left[\begin{array}{cccc}
a_{1 n}^{1} & a_{1 n}^{2} & \cdots & a_{1 n}^{L} \\
a_{2 n}^{1} & a_{22}^{2} & \cdots & a_{2 n}^{L} \\
\cdots & \cdots & & \cdots \\
a_{M n}^{1} & a_{M n}^{2} & \cdots & a_{M n}^{L}
\end{array}\right], \quad n=1,2, \cdots, N
$$

Step 3: calculate the emergency committee evaluation group according to the $n$ attribute optional subject Borda points after the evaluation matrix $B_{n}^{B}$.

$$
B_{n}^{B}=\left[\begin{array}{cccc}
M & M & \cdots & M \\
M & M & \cdots & M \\
\cdots & \cdots & & \cdots \\
M & M & \cdots & M
\end{array}\right]_{M \times L}-B_{n}, \quad n=1,2, \cdots, N
$$

$B_{n}^{B} \quad$ line $m(m=1,2, \cdots, M)$ of column $l(l=1,2, \cdots, L)$ element $b_{m l}^{n}$ represents the $l$ assessment team to $n$ in the $m$ optional subject attribute evaluation Borda points, its meaning is: from the $l$ evaluation team, in the $n$ attribute of the first $m$ alternative is better than that of other optional subject number.

Step 4: calculate the $m$ attribute the $n$ optional subject Borda point 
$b_{m}^{n}=\sum_{l=1}^{L} b_{m l}^{n}$, compose matrix $B^{B}=\left[b_{m}^{n}\right]_{M \times N}$. By $b_{m}^{n}(m=1,2, \cdots, M)$ under the size can be scheduled to start the $n(n=1,2, \cdots, N)$ attribute of the pros and cons of each alternative subject order $k(k=1,2, \cdots, M), b_{m}^{n}$ is the optimal decision-making body.

$$
B^{B}=\left[\begin{array}{cccc}
b_{1}^{1} & b_{1}^{2} & \cdots & b_{1}^{N} \\
b_{2}^{1} & b_{2}^{2} & \cdots & b_{2}^{N} \\
\cdots & \cdots & & \cdots \\
b_{M}^{1} & b_{M}^{2} & \cdots & b_{M}^{N}
\end{array}\right]
$$

Step 5: define the $n(n=1,2, \cdots, N)$ properties under the consistency of the matrix $C^{n}=\left[c_{m k}^{n}\right]_{M \times N}$, the elements of the $c_{m k}^{n}$ value according to the following rules: when according to the $b_{m}^{n}$ will be the $m$ alternative when the subject was ranked the $k, c_{m k}^{n}$ is one, otherwise $c_{m k}^{n}$ is 0 , so the $C^{n}$ elements of each row (or column) to 1 , the one and only one element in the rest are.

Step 6: calculation of weighted consistency matrix of all attributes $D=\left[d_{j k}\right]_{M \times N}=\sum_{n=1}^{N} \omega_{n} \times C_{n}$.

Step 7: each candidate for the subject of final order. Since each optional subject only in a certain position, also can row a decision-making subject in each position, available 0 - 1 programming to solve as follows:

$$
\begin{aligned}
& \max \sum_{j=1}^{M} \sum_{k=1}^{M} d_{j k} x_{j k} \\
& \text { s.t. } \\
& \sum_{j=1}^{M} x_{j k}=1, \quad k=1,2, \cdots, M \\
& \sum_{k=1}^{M} x_{j k}=1, \quad j=1,2, \cdots, M \\
& x_{j k} \in\{0,1\}, \quad j, k=1,2, \cdots, M
\end{aligned}
$$

$x_{j k}=1$ represents the first solution to the problem of $j$ a subject should be in $k$.

\section{Conclusions}

In this paper, we analyze the sudden disaster emergency collaborative decisionmaking subject influence factors, design the emergency collaborative decisionmaking subject choice of evaluation indicator system, and through the method of multi-attribute group decision-making subject evaluation model to evaluate. This paper puts forward the indicator system and multiple attribute group decision-making model of choice for emergency collaborative decision-making subject has certain guiding significance and reference value, and easy to understand and calculate. It is important to note that the sudden disasters normally need only a collaborative decision-making, so through multiple attribute group decision making model in the first place of the main body is the optimal solution, 
does not exclude the special situation needs two or more of the decision-making subject of public decision-making, this paper established the multiple attribute group decision making model can also solve the problem, that is, the result of the top two in the subject is the need to choose the two decision-making subject, and so on.

If the $B^{B}$ approximation as emergency committee evaluation team for all possible subject all attributes of the quantitative evaluation of value, and then use generally weighted sum method to solve, also can come to the conclusion that the same as the above model, it also suggests that the validity of the model.

\section{Acknowledgements}

This article could not have been completed without the help and support of many people. We express our deepest gratitude to the reviewers and editors, whose able guidance helped in the publication of this article. This work is supported by National Social Science Fund (Grant No. 14BGL062), National Science \& Technology Pillar Program during the 12th Five-year Plan Period (Grant No. 2014BAL07B04, 2014BAL07B05) and Henan University of Technology Highlevel Personnel Funds (Grant No. 2015SBS014).

\section{References}

[1] Elfithri, R. and Mokhtar, M.B. (2002) Collaborative Decision Making Issues in Sustainable Water Resources Management: A Case Study on Langat Basin. Proceedings of the International Conference on Environmental Management. Ten Years after Rio, 10, 304-314.

[2] Bernier, J. (2003) Decisions and Attitude of Decision Makers Facing Hydrological Risk. Hydrological Science Journal, 6, 301-316. https://doi.org/10.1623/hysj.48.3.301.45284

[3] Manassero, G., Semeraro, Q. and Tolio, T. (2004) A New Method to Cope with Decision Makers' Uncertainty Technology. Equipment Selection Prices. CIRP Annals-Manufacturing, 1, 389-392.

[4] Huang, D.J. and Li, C.G. (2008) Research on the Coordination in City Major Accident Emergency Management. Safety, 29, 18-20.

[5] Tan, X.Q. and Chen, G.H. (2009) The Ways to Achieve Coordination Mechanism in Cross-regional Emergencies. Journal of Institute of Disaster-Prevention Science and Technology, 11, 76-79.

[6] Kang, K., Chen, T. and Yuan, H.Y. (2016) Cooperative Scheduling Model for MultiLevel Emergency Response Teams. Journal of Tsinghua University (Sci \& Tech), 56, 830-835.

[7] Chen, X., Wang, Y., Wu, L.Y., Yan, G.Y. and Zhu, W. (2010) Emergency Decision Model with Multiple Stages, Multiple Objectives and Multidivisional Cooperation. Systems Engineering Theory and Practice, 30, 1977-1985.

[8] Du, L., Wang, W.J., Dong, C.X., Li, L.X. and Gao, S. (2010) Emergency Collaborative Petri Net Modeling and Collaborative Detection Based on Multi-Agent System. Journal of Computer Applications, 30, 2567-2571. https://doi.org/10.3724/SP.J.1087.2010.02567

[9] Liu, Y., Zhou, Q., Su, G.F., Liu, X. and Liu, L.M. (2010) Simulation of Synergetic 
Mechanism in Emergency Response Based on Multi-Agent Method. Journal of Tsinghua University (Sci \& Tech), 50, 165-169.

[10] Liu, H.Q., Sha, Y.Z. and Liu, Q. (2011) The Construction of Multi-Agency and CoOrdination Mechanism in Emergency Management: Three Perspectives. Journal of Intelligence, 4, 18-23.

\section{Scientific Research Publishing}

Submit or recommend next manuscript to SCIRP and we will provide best service for you:

Accepting pre-submission inquiries through Email, Facebook, LinkedIn, Twitter, etc. A wide selection of journals (inclusive of 9 subjects, more than 200 journals)

Providing 24-hour high-quality service

User-friendly online submission system

Fair and swift peer-review system

Efficient typesetting and proofreading procedure

Display of the result of downloads and visits, as well as the number of cited articles Maximum dissemination of your research work

Submit your manuscript at: http://papersubmission.scirp.org/

Or contact jssm@scirp.org 